\title{
Mediating effects of self-esteem in the relationship between attachment styles and social media addiction among university students
}

\author{
Zeynep Isil Demircioglu' ${ }^{\circledR}$, Asli Goncu Kose ${ }^{1 \odot}$ \\ ${ }^{1}$ Cankaya University, Faculty of Arts and Sciences, Department of Psychology, Ankara - Turkey
}

\begin{abstract}
Objective: In the present time, internet and social media have become indispensable parts of our lives. Apart from the advantages of social media, some individuals have begun to suffer from Social Media Addiction (SMA) which is associated with dysfunctions in academic and/or work domains. Although outcomes of SMA have been relatively widely investigated, its predictive factors have not been studied extensively yet. The aim of the present study was to investigate the effects of secure, fearful, and preoccupied attachment styles on SMA and the mediating role of self-esteem in the links between attachment styles and SMA.
\end{abstract}

Method: Data were collected from 455 university students (300 females, 155 males) who volunteered to complete the survey package that included SMA Scale, Relationships Questionnaire, and Rosenberg Self-Esteem Scale.

Results: The data were analyzed using Structural Equation Modeling and moderated multiple regression. The results revealed that preoccupied and fearful attachment had significant positive direct effects on SMA. While the link of preoccupied attachment with SMA was partially mediated, the relationship between secure attachment and SMA was fully mediated by selfesteem. In addition, exploratory analyses revealed that gender moderated the relationship between self-esteem and SMA.

Conclusion: The findings of this study suggest that fearful attachment and preoccupied attachment can be risk factors for SMA among university students. On the other hand, being securely attached and having high self-esteem can be protective factors for SMA.

Keywords: Adult attachment styles, gender, self-esteem, social media addiction

\section{INTRODUCTION}

Social media have become an almost inevitable part of our lives. They play a crucial role in our daily activities as well as being a vital means of functioning for some individuals. According to Turkish Statistics Institute data for 2019, the purpose of $81.4 \%$ of internet users is to participate in social networks (e.g., creating user profiles, posting messages, or other contributions) (1).
Recent studies have revealed that although social media have certain advantages such as increased communication and knowledge sharing, some individuals are likely to develop and suffer from social media addiction (SMA) (2). SMA can be differentiated from regular or non-problematic social media use by sufferers' inability to control their use of social media and using social media to an extent that interferes with their social and professional functioning (3). In another

How to cite this article: Demircioglu Zl, Goncu Kose A. Mediating effects of self-esteem in the relationship between attachment styles and social media addiction among university students. Dusunen Adam The Journal of Psychiatry and Neurological Sciences 2020;33:8-18.

Correspondence: Asli Goncu Kose, Cankaya University, Faculty of Arts and Sciences, Department of Psychology, Ankara - Turkey

Phone: +90 3122331451 E-mail: agoncu@cankaya.edu.tr

Received: August 01, 2019; Revised: August 29, 2019; Accepted: December 10, 2019 
conceptualization, SMA was defined as being overly concerned with social media, having a strong urge to $\log$ on to and/or use social media, and experiencing impairments in social functioning, academic or work life, interpersonal relationships, and/or psychological well-being due to excessive social media use (4). Although few in number, there are studies that have focused on personality traits (5), self-esteem (6), and attachment (7) as predictors of SMA. For example, in one study, secure attachment style was found to be a protective factor for SMA and insecure attachment styles were found to be among the predictors for SMA (8). Aim of the present study was to examine the effects of attachment styles on SMA and to investigate the mediating role of self-esteem in the proposed links. It was suggested that insecure attachment styles would be both directly and indirectly associated with SMA through their negative effects on self-esteem, whereas secure attachment would be both directly and indirectly related to SMA via its positive influence on self-esteem.

Attachment can be defined as the bond established through the relationship between newborn and caregiver or the urge of the newborn to establish a relationship with a caregiver (9). The caregiver's emotional accessibility from the newborn's perspective and the newborn's expectation regarding his or her worthiness of love and care determine the newborn's attachment style (10). Bowlby (9) defines these two independent dimensions as "model of others" and "model of self," respectively. These two dimensions are used to form the "Four Category Model of Attachment," including secure, preoccupied, dismissive-avoidant, and fearful-avoidant attachment styles (11). Securely attached individuals' model of others and model of self are both positive. Preoccupied, dismissive, and fearful attachment styles are insecure attachment styles. Preoccupied attachment style is characterized by a positive model of others and a negative model of self. Individuals with preoccupied attachment generally ruminate about their relationships, their self-esteem is fragile, and they desperately desire acceptance and approval by others. In dismissive attachment, the individual's model of self is positive while the model of others is negative. They generally tend to avoid intimacy and close relationships because of their belief that others are unworthy of being loved. Lastly, in a fearful attachment style both model of self and model of others are negative. Individuals tend to think that they are not worthy of being loved by others and generally fear to establish close relationships (11). Early attachment styles established with the primary caregiver (in most cases with the mother) that shape the future are prototypes of adult relationships and adult attachment styles (12).

It is suggested that individuals with insecure attachment styles are more likely to have fear of failure in actual or real-world social interactions than those with secure attachment (13). Moreover, they tend to avoid face-to-face communication because of their self and other schemas and are more likely to prefer social relationships formed via social media over face-to-face communications (14). In time, their behavior is likely to be reinforced through relatively more successfully established social interactions on social media where people can even pretend to be someone else with socially desired characteristics in contrast to their social relationships in real settings.

Individuals with preoccupied attachment may seek reassurance by switching from their negative image of self to a positive image with the help of positive feedback. Furthermore, these individuals have the opportunity to think more about what they want to say when communicating through social media and they can express themselves better; in this way, their view of self can be more positive (7). Individuals with a fearful avoidant attachment style tend to have high level of anxiety related to the possibility of rejection by others (11), and using social media to communicate may provide them with an opportunity to increase acceptance. Furthermore, being rejected on social media may be less harmful than being rejected in faceto-face relations for these individuals. The idea that receiving acceptance instead of rejection is very likely may soften a negative image of self.

Thus, individuals with insecure attachment styles are more likely to be at risk of excessive social media use and addiction than those with secure attachment style. In line with these propositions, previous studies revealed that attachment anxiety was a predictor of excessive Facebook use (15), and individuals with insecure attachment styles used Facebook more frequently than those who were securely attached (16). In addition, in late adolescence insecure attachment was a predictor of SMA (17). Furthermore, anxious and avoidant attachment styles were reported to be risk factors for SMA (7). Studies examining the links of different types of insecure attachment with SMA are very rare. In one of these studies, JenkinsGuarnieri et al. (16) reported that there was no significant association between dismissing attachment and SMA. Nitzburg and Farber (18) suggested that 
avoidant attachment style may be linked to SMA only when it is accompanied by attachment anxiety. Therefore, in the present study it is hypothesized that the association between SMA and secure attachment would be negative while it would be positive with preoccupied and fearful attachment. The relationship between dismissive attachment and SMA is expected to be non-significant.

Self-esteem can be defined as a general assessment of one's own worth and global feelings of competence and self-acceptance (19). Low self-esteem leads to negative consequences such as depression, anxiety, nicotine dependence (20); on the other hand, high self-esteem is related to happiness (21), life satisfaction, and well-being (22). When looking at the predictors of self-esteem, it was found that parent-child closeness and affection expressed by parents are associated with high self-esteem (23). Furthermore, there are numerous studies showing significant links between attachment styles and self-esteem (24-27). These links are explained by schema or model of self that characterizes attachment styles. A positive and trustbased relationship with the parents (or with the attachment figure) helps individuals develop and internalize 'self' as competent and loveable (26). The 'Model of self' is positive for individuals with secure attachment while it is negative for both individuals with fearful and with preoccupied attachment styles. Therefore, it is expected that the association between self-esteem and secure attachment style would be positive whereas it should be negative with preoccupied and fearful attachment styles.

According to sociometer theory, humans have a congenital desire to contact others due to a need of acceptance and belonging (28), and regardless of their self-esteem levels, individuals have the desire to connect (29). Individuals having a high level of self-esteem easily satisfy this desire through daily and face-to-face relations, while this is much more difficult to achieve in the same way for individuals with low self-esteem, the reason being that in contrast to people with high selfesteem, those with low self-esteem have high levels of social anxiety and are likely to be more introverted and shyer (30). Social media can help individuals with low self-esteem to sustain a better social life (31) by providing self-disclosure opportunities (32). In addition, they may increase the possibility of getting positive answers or comments from others since even an ideal self can easily be presented on social media. Consistently, individuals who have low self-esteem may use social media to increase their feelings of self-worth via positive comments. In line with these propositions, previous studies revealed negative links of self-esteem level with social media use $(31,33,34)$ and with SMA (35). Therefore, in the present study it is suggested that self-esteem would be negatively associated with SMA and that self-esteem would partially mediate the relationship of secure, preoccupied and fearful attachment styles with SMA (Figure 1).

\section{METHOD}

\section{Participants and Procedure}

Approval for the study was obtained from Cankaya University Scientific Research and Publication Ethics Committee. Data were collected from 470 university students; but 15 of them were excluded from the main analyses because of incomplete data, leaving 455 individuals (155 males [34\%], 300 females [66\%]) enrolled in six different universities in Turkey being included in the study. The students from different departments of two foundation universities in Ankara, Turkey, were recruited as participants, and those who volunteered to participate were given additional course credits. In order to provide the students with equal opportunity for extra course credits, students who did not want to participate were given an opportunity to get the same credit either by providing contact information

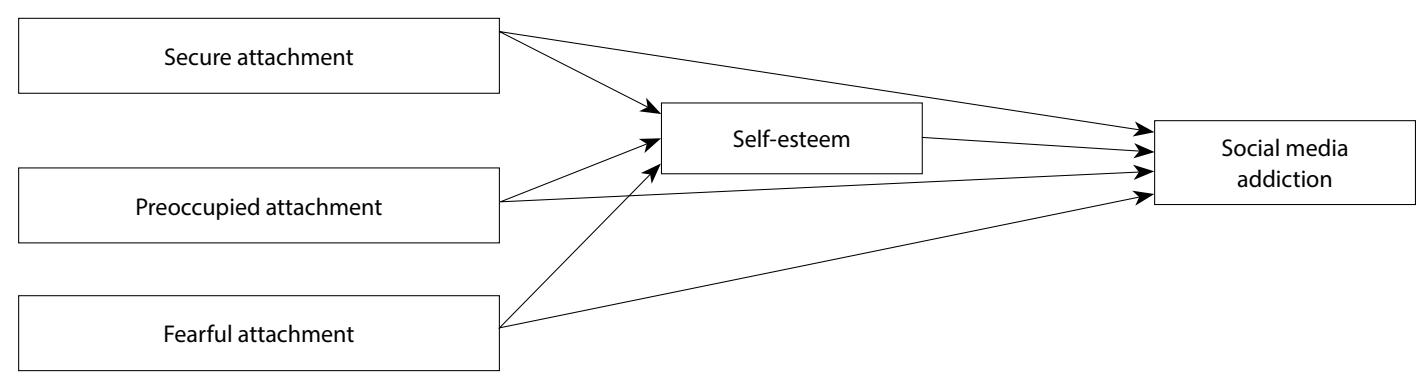

Figure 1. Proposed model of the study variables (M1). 
of friends who would like to be participants or by making a five-minute course-relevant presentation. Informed consent of all the participants was received via a form. The survey package included sections regarding measures of SMA, adult attachment styles, self-esteem, and a demographic information section that included questions regarding age, gender, major subject of study, the most preferred social networking site, duration of social media use, and (average) daily time spent on social media. Participants' ages ranged from 18 to 42 years, with a mean of $21.36(S D=2.20)$. Their demographic characteristics, information regarding most preferred social networking site, and descriptive statistics regarding the duration of social media use and (average) daily time spent on social media are presented in Table 1.

\section{Measures}

Social Media Addiction Scale: SMA was measured using a 41-item SMA Scale developed in Turkish (36), and the responses were given using a 5-point Likert scale ranging from " $1=$ never" to " $5=$ always." The scale consists of 4 subscales which are preoccupation, mood modification, relapse, and conflict/problems. The preoccupation subscale includes 12 items, for example "I spend more time on social media than I intend to." The mood modification subscale consists of 5 items, e.g., "I spend time on social media when I feel alone." The relapse subscale includes 5 items such as "I try to stop using social media, but I cannot." Finally, the conflict/problems subscale consists of 19 items, including "I neglect school or work-related tasks to spend more time on social media." Cronbach's alpha coefficient of the scale was 0.96 .

Relationships Questionnaire (RQ): Adult attachment styles were measured with the RQ (11) which was adapted to Turkish by Sumer and Gungor (37). The scale consists of 4 items and each item corresponds to one of the four attachment styles. Participants reported their answers using a 7-point Likert-type scale ranging from " $1=$ does not describe me at all" to " $7=$ fully describes me". The questionnaire was administered in various cultural contexts by several studies outside (38-40) as well as inside Turkey (41-43), suggesting that it can be considered a valid measure of adult attachment.

Rosenberg Self-Esteem Scale (RSES): Self-esteem was measured using the 10-item RSES (19), which was

Table 1: Participants' descriptive statistics $(n=455)$

\begin{tabular}{|c|c|c|c|c|}
\hline & Frequency & Percentage & Mean & SD \\
\hline \multicolumn{5}{|l|}{ Gender } \\
\hline Female & 300 & 66 & & \\
\hline Male & 155 & 34 & & \\
\hline \multicolumn{5}{|c|}{ Duration of social media use } \\
\hline Less than 1 year & 18 & 4.0 & & \\
\hline $1-2$ years & 37 & 8.1 & & \\
\hline $3-4$ years & 103 & 22.6 & & \\
\hline More than 5 years & 292 & 64.2 & & \\
\hline No information & 5 & 1.1 & & \\
\hline \multicolumn{5}{|c|}{ Daily time spent on social media } \\
\hline Less than 1 hour & 108 & 23.7 & & \\
\hline $1-3$ hours & 248 & 54.5 & & \\
\hline $4-6$ hours & 81 & 17.8 & & \\
\hline More than 7 hours & 13 & 2.9 & & \\
\hline No information & 5 & 1.1 & & \\
\hline \multicolumn{5}{|c|}{ Most preferred social networking site } \\
\hline Instagram & 363 & 79.8 & & \\
\hline Twitter & 43 & 9.5 & & \\
\hline Facebook & 23 & 5.1 & & \\
\hline Others & 26 & 5.6 & & \\
\hline Age & & & 21.36 & 2.20 \\
\hline
\end{tabular}


adapted to Turkish by Cuhadaroglu (44). A sample item of the subscale is "I have a positive attitude toward myself." Participants reported their answers on a 4 -point Likert-type scale ranging from " $1=$ strongly disagree" to " $4=$ strongly agree". Cronbach's alpha coefficient of the subscale was 0.86 .

\section{Statistical Analysis}

Data were analyzed using SPSS-24 and AMOS 24.0 (45). Before the scale scores were calculated, descriptive statistical analyses and reliability analyses of the measures were performed and Cronbach's alpha reliabilities of the scales were estimated. Mean values, standard deviations of the scores, and a correlation matrix were analyzed by SPSS ver. 24 , and it was noted that the $\mathrm{p}$ value was greater than 0.95 indicating an acceptable threshold of significance. Then, Structural Equation Modeling (SEM) technique was utilized in order to test the hypothesized mediated model by using AMOS 24.0 (45).

\section{RESULTS}

\section{Descriptive Statistics and Correlations among the Study Variables}

Means, standard deviations of the scores, and the correlation matrix are given in Table 2 . The relationship between secure attachment and SMA was not significant; therefore, Hypothesis la was not supported. Supporting Hypotheses $1 \mathrm{~b}$ and $1 \mathrm{c}$, fearful and preoccupied attachment was found to be positively associated with SMA $(\mathrm{r}=0.20, \mathrm{p}<0.01 ; \mathrm{r}=0.22, \mathrm{p}<0.01$, respectively). Dismissive attachment was not significantly associated with SMA; thus, Hypothesis 1d was also supported. Secure attachment had a positive correlation with self-esteem $(\mathrm{r}=0.22, \mathrm{p}<0.01)$; fearful and preoccupied attachment had a negative correlation with self-esteem $(\mathrm{r}=-0.19, \mathrm{p}<0.01 ; \mathrm{r}=-0.24, \mathrm{p}<0.01$, respectively). These results point out that Hypothesis 2 was fully supported. Furthermore, consistent with
Hypothesis 3a, self-esteem and SMA were found to be negatively correlated $(\mathrm{r}=-0.32, \mathrm{p}<0.01)$. As explained below, Hypothesis 3b, which suggested that the correlations of secure, fearful and preoccupied attachment styles with SMA would be partially mediated by self-esteem, was tested with SEM technique.

\section{Testing the Proposed Mediated Model}

SEM was used in order to test the hypothesized heuristic model (M1) and the modified model (M2). In the literature, CFI, NFI and the TLI were the most common fit indices that were reported to test the model (46). In addition, Chi-Square statistics, its degrees of freedom and $\mathrm{p}$ value, and the RMSEA should be used while reporting the results and acceptable thresholds which were suggested to be greater than 0.95 for CFI, NFI and TLI, and lower than 0.07 for RMSEA, while the $\mathrm{p}$ value should be greater than 0.05 (47). The scaled chi-square was not used since the analyses were run with AMOS 24.0.

The initial results regarding M1 showed that the proposed model poorly fit the data $\left(\chi^{2}[n=455\right.$, $\mathrm{df}=3]=75.59, \mathrm{TLI}=0.62, \mathrm{CFI}=-0.28, \mathrm{NFI}=0.62$, RMSEA $=0.23 ; \mathrm{p}<0.001)$. The modification indices suggested that the error term of preoccupied attachment style should be allowed to covary with the error term of fearful attachment style; and the error term of fearful attachment style should be allowed to covary with the error term of secure attachment style. After correlating the error terms mentioned above, the M1 fit the data well $\left(\chi^{2}[\mathrm{n}=455, \mathrm{df}=3]=0.63\right.$, TLI $=1.02, \mathrm{CFI}=1.00$, $\mathrm{NFI}=0.99$, RMSEA $=0.00 ; \mathrm{p}>0.05)$. However, only the paths from secure attachment and preoccupied attachment to self-esteem $(\beta=0.19, p<0.001 ; \beta=-0.22$, $\mathrm{p}<0.001$; respectively) and from fearful attachment, preoccupied attachment, and self-esteem to SMA were significant $(\beta=0.13, p<0.01 ; \beta=0.12, p<0.01 ; \beta=-0.28$, $\mathrm{p}<0.001$, respectively), and since the model was a saturated model, no modification indices were obtained.

Table 2: Descriptive statistics, intercorrelations, and internal consistencies of the study variables ( $n=455)$

\begin{tabular}{|c|c|c|c|c|c|c|c|}
\hline & Mean & SD & 1 & 2 & 3 & 4 & 5 \\
\hline 1. Secure attachment & 3.64 & 1.90 & - & & & & \\
\hline 2. Fearful attachment & 3.70 & 1.88 & $-0.29^{*}$ & - & & & \\
\hline 3. Preoccupied attachment & 3.21 & 1.80 & -0.04 & $0.27^{*}$ & - & & \\
\hline 4. Dismissive attachment & 3.20 & 1.84 & 0.04 & $0.22 *$ & 0.04 & - & \\
\hline 5. Rosenberg Self-Esteem Scale & 3.11 & 0.58 & $0.22^{*}$ & $-0.19^{*}$ & $-0.24^{*}$ & -0.05 & - \\
\hline 6. Social Media Addiction Scale & 2.18 & 0.70 & -0.07 & $0.20 *$ & $0.22 *$ & 0.03 & $-0.32^{*}$ \\
\hline
\end{tabular}

${ }^{*}$ Correlation is significant at the $p<0.01$ level (2-tailed). SD: Standard deviation 
The second model (M2) after removing the nonsignificant paths provided good fit to the data as well $\left(\chi^{2}[\mathrm{n}=455, \mathrm{df}=3]=3.72, \mathrm{TLI}=0.99, \mathrm{CFI}=0.99, \mathrm{NFI}=0.98\right.$, RMSEA $=0.02 ; \mathrm{p}>0.05)$ and was accepted as the final model (Figure 2). Partially supporting the hypotheses, the link of preoccupied attachment with SMA was partially mediated by self-esteem. In addition, selfesteem fully mediated the relationships of secure attachment with SMA. Furthermore, preoccupied attachment and secure attachment had significant indirect effects on SMA (indirect effect size for preoccupied attachment $=0.04, \mathrm{p}<0.05$; indirect effect size for secure attachment $=0.03, \mathrm{p}<0.05$ ).

In addition to the main analyses, a series of post-hoc analyses was conducted. Firstly, gender differences in the scores of the main variables were examined by conducting independent samples t-tests. The female and male sample sizes in the present study were not equal. However, many studies tested gender effects with unequal sample sizes (48). Therefore, exploratory analyses testing the moderating effects of gender on the relations of attachment styles with SMA and on the links of self-esteem with SMA were conducted with the data of the original sample, rather than randomly deleting participants for the analysis to make the sample sizes equal. The results showed that gender had a significant main effect on SMA, self-esteem, preoccupied attachment, and fearful attachment scores. That is to say, females scored significantly higher than males on SMA, self-esteem and fearful attachment; while males scored significantly higher than females on preoccupied attachment (Table 3).

Secondly, as gender had main effects on four of the main variables, moderating roles of gender in the links

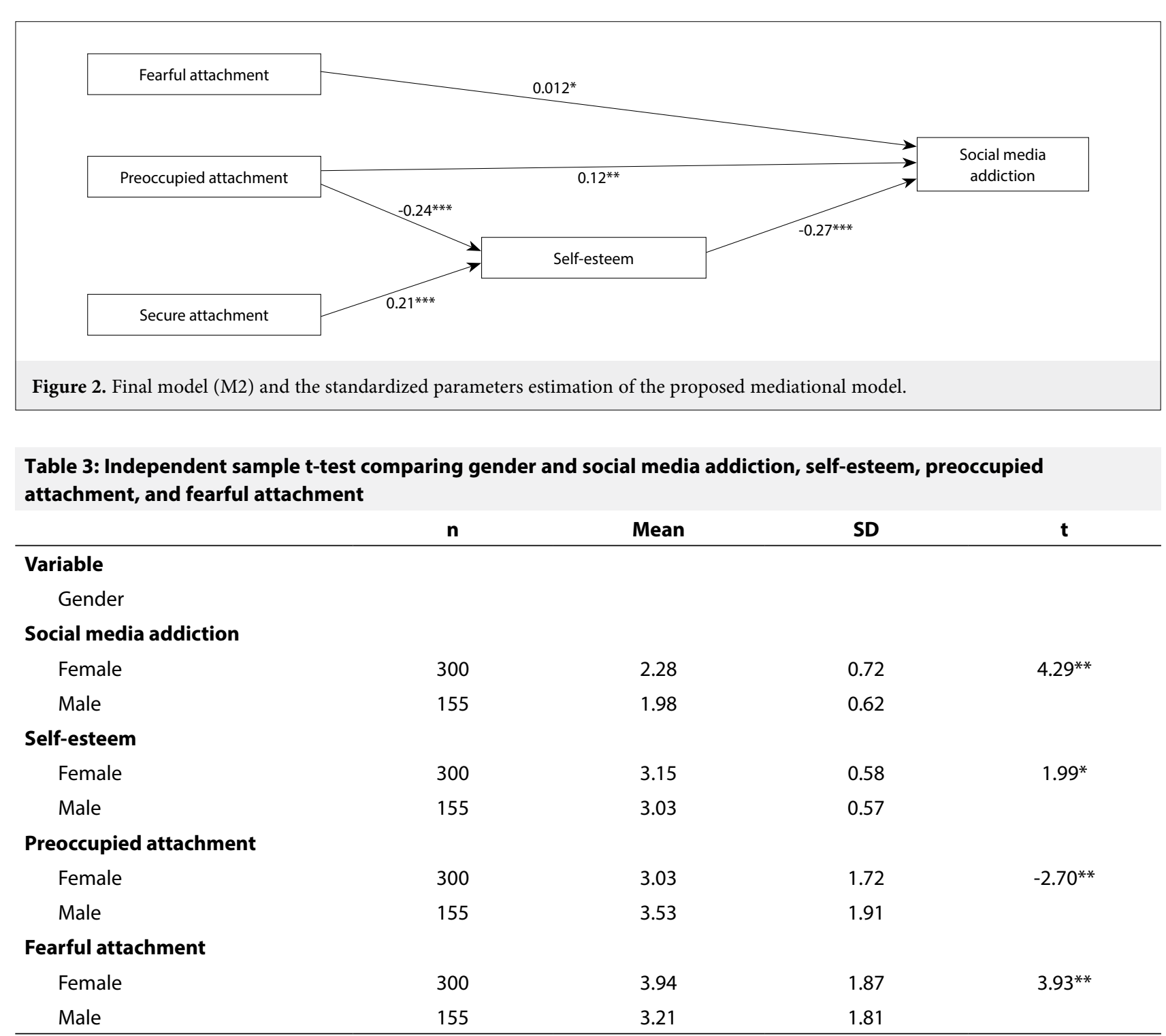

*Significant at the $p<0.05$ level. **Significant at the $p<0.001$ level. SD: Standard deviation 


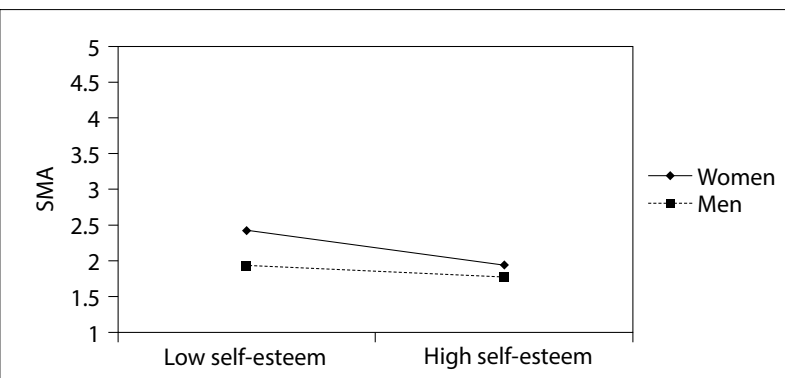

Figure 3. The interaction effect of self-esteem and gender on SMA.

of attachment styles and self-esteem with SMA were examined by conducting moderated multiple regression analyses. The findings revealed that gender moderated the relationship between self-esteem and SMA in such a way that females who had high levels of self-esteem were less likely to score high on SMA than females with low self-esteem $(F[1,450]=30.31, \mathrm{p}<0.05)$. Females with both low and high self-esteem scored higher on SMA than males and males reported similar SMA scores regardless of their self-esteem level (Figure 3).

\section{DISCUSSION}

Considering that SMA is a problem spreading across most cultural contexts and that attachment is likely to contribute significantly to our understanding of the underlying mechanisms of SMA, it is important to investigate the links of attachment styles with SMA empirically. The general aims of using social media are to establish and maintain social relations on online platforms. Adult attachment styles based on early attachment experiences (49) are likely to explain the main patterns of the formation of social relationships. In this respect, they are also likely to affect both the extent of social media use as well as attitudes towards and aims of using social media. Although recent research confirmed that there were differential links between specific attachment styles and SMA $(7,50,51)$, these studies are limited in number. In the same way, there are only a few research projects that focus on these relationships in Turkey (52). The present study aimed at investigating the direct links of adult insecure attachment styles with SMA and to reveal the indirect effects of adult attachment styles on SMA through their influences on self-esteem. As expected, preoccupied and fearful attachment were significant predictors of SMA. Moreover, self-esteem partially mediated the relation of preoccupied attachment with SMA. That is to say, individuals who were high in preoccupied and fearful attachment style were more likely to have high scores on SMA. In addition, individuals who had a preoccupied attachment style were likely to have low levels of self-esteem, which, in turn, was positively associated with SMA. Furthermore, the relationship between secure attachment and SMA was fully mediated by self-esteem. It can be argued that secure attachment may be a protective factor for SMA only through its positive effect on self-esteem. Thus, the present study contributes to the literature by revealing one of the key psychological mechanisms (i.e., self-esteem) that would explain the negative link of secure attachment with SMA.

In previous studies, the findings investigating the relationship between attachment styles and behavioral addictions (internet addiction and SMA) were complicated. In adolescents, secure attachment was found to be a protective factor for internet addiction, while on the other hand, insecure attachment styles were found to be risk factors for internet addiction (53). Similarly, it was found that insecurely attached individuals' inclination towards pathological internet usage is significantly higher than in securely attached individuals (54). In another research, it was found that secure attachment was negatively associated with internet and SMA. However, preoccupied attachment was not found to be significantly associated with internet and SMA $(51,8)$. In a relatively recent study, only preoccupied attachment style was found to be a predictor for problematic internet use (55).

As expected, the present study found preoccupied attachment to be positively associated with SMA both directly and through its negative effect on self-esteem. However, although bivariate correlation between fearful attachment and self-esteem was negative and significant, self-esteem did not (either partially or fully) mediate the link of fearful attachment style with SMA. In addition, fearful attachment was directly and negatively associated with SMA. Different combinations of working models of self and others characterizing these two insecure attachment styles underlying these findings may explain this observation. Individuals with both attachment styles have negative models of self. However, different from preoccupied individuals who have positive working model of others, fearful individuals' working model of others is negative, and it is argued that this may make them likely to avoid intimate personal relationships deliberately in an attempt to avoid being hurt or rejected (56). Independent of their level of self-esteem, this tendency is likely to make them more vulnerable for SMA since social media provide them a relatively more "secure" 
interpersonal context than offline, face-to-face relationships. In other words, not low levels of selfesteem but fearfully attached individuals' negative model of others may be the main risk factor for their vulnerability for SMA.

Consistent with the present research, previous studies also revealed that preoccupied attachment was a predictor of SMA in late adolescence (15). The present study contributes to the literature by revealing the significant main effects of both preoccupied and fearful attachment styles on SMA in young adulthood and by uncovering the fully mediated relationship between secure attachment and SMA via self-esteem. Previous studies revealed the directions of the associations of insecure and secure attachment with SMA; however, underlying mechanisms by which these attachment styles were related to SMA have not yet been fully understood. By pointing out self-esteem as one of the key mechanisms involved in the relations of attachment styles with SMA, this study is thought to be one of the first attempts in this direction. Further research is needed to reveal other mediating factors in the links of attachment styles with SMA. As an illustration, selfesteem stability or motivational tendencies such as need for affiliation and/or need for approval can be examined as potential mediators of the links between attachment styles and SMA.

Another contribution of the present study is to reveal significant gender differences in SMA through exploratory analyses. Women's SMA scores were significantly higher than men's. This finding implies that females may form the main risk group for SMA. However, the underlying psychological mechanisms that contribute to this gender difference should be explored in further research. In addition, future studies are suggested to focus on the purposes of using social media to understand the possible reasons of this gap between females and males. Finally, males who seem to be less likely to be at risk for SMA may be in the risk group for another online addiction, namely, online gaming addiction. To illustrate, in a study conducted in Norway, Andreassen et al. (57) found that males were significantly more likely to be addicted to playing video games than females, while females were significantly more likely to be addicted to social media use than males. The findings of the present research are consistent with their results. However, the number of empirical studies focusing on effects of gender on addictive online behaviors is relatively low, and future research is recommended to replicate and elaborate on previous findings by employing varied research designs and samples from other cultural contexts.

Furthermore, we found that the relation between self-esteem and SMA was moderated by gender: Females generally had higher SMA scores than males and females with low self-esteem got significantly higher scores on SMA than women with high selfesteem. On the other hand, males with low and high self-esteem had similar SMA scores. These findings may imply that low self-esteem significantly contributes to females' over-involvement in social media, which probably serve as a practical and reinforcing alternative to face-to-face communications for women with low self-esteem. In other words, females with low selfesteem may be likely to avoid direct communication channels that they perceive as highly stressful. In line with the propositions of reinforcement theory (58), social media providing them with opportunities for less stressful and more rewarding communication experience may gradually become their primary communication tool.

Findings in the current study regarding the positive correlations of fearful and preoccupied attachment with SMA were generally consistent with the previous literature. However, contrary to previous studies that revealed direct association between secure attachment and SMA and/or internet addiction, the present study showed that self-esteem fully mediated the relationship between secure attachment and SMA. As suggested above, the present findings are believed to contribute to our understanding of the underlying psychological mechanism in the relation of secure attachment and SMA. Nevertheless, although secure attachment seems to be a protective factor for internet addiction and/or SMA, securely attached people may be more likely to use social media extensively as well in order to strengthen their actual relations. Therefore, future studies are suggested to focus on the relationships between attachment styles and the aims of using social media.

With the increasing use of social media, SMA is argued to have potentially adverse effects. Determination of the possible causes of SMA will not only contribute to existing scientific knowledge but also help practitioners to design and implement successful interventions. One of the practical implications of the study may be to sensitize practitioners regarding insecure attachment styles when they attempt to intervene in SMA. In addition, considering the mediating roles of self-esteem in the relation of attachment styles and SMA, practitioners are suggested 
to focus on the problems related to self-esteem in their attempts to treat SMA among both adolescents and adults.

Just like every research, the present study has certain limitations. First, the sample is moderate in size and the data were based on self-report. For the future, studies are proposed that gather both self-report data and data from participants' significant others when measuring SMA. Second, the study employed cross-sectional design and attempted to reveal causal relationships. However, because self-esteem and attachment styles are stable characteristics developed in early ages $(9,59)$, individuals' attachment styles and self-esteem levels are more likely to affect SMA rather than vice versa. Yet, future studies are suggested to examine the proposed model by employing a longitudinal design. Third, the age range of the participants was limited as all of them were undergraduate students. Thus, while previous studies showed the highest prevalence rate of SMA in this age group (60), future studies might benefit from testing the proposed model with samples from various age groups.

In conclusion, the present study is a modest attempt to investigate the effects of attachment styles on SMA and the mediating role of self-esteem in the proposed relationships. By revealing the positive direct effects of fearful and preoccupied attachment styles on SMA and the mediating roles of self-esteem in the links of secure attachment and preoccupied attachment with SMA, the study is destined to contribute to the SMA literature and its practical application.

\begin{tabular}{|c|c|c|}
\hline \multicolumn{2}{|c|}{ Contribution Categories } & Author Initials \\
\hline \multirow{3}{*}{ Category 1} & Concept/Design & Z.I.D., A.G.K. \\
\hline & Data acquisition & Z.I.D. \\
\hline & Data analysis/Interpretation & A.G.K. \\
\hline \multirow{2}{*}{ Category 2} & Drafting manuscript & Z.I.D. \\
\hline & Critical revision of manuscript & A.G.K. \\
\hline Category 3 & Final approval and accountability & A.G.K., Z.I.D. \\
\hline \multirow{2}{*}{ Other } & Technical or material support & A.G.K., Z.I.D. \\
\hline & Supervision & A.G.K. \\
\hline
\end{tabular}

Ethics Committee Approval: Approval for the study was obtained from Cankaya University Scientific Research and Publication Ethics Committee.

Informed Consent: No patients were participated in the study.

Peer-review: Externally peer-reviewed.

Conflict of Interest: As the authors we declare that we have no conflict of interest.

Financial Disclosure: No financial support was received.

\section{REFERENCES}

1. Turkish Statistical Institute (TUIK). Internet activities of individuals who have accessed the Internet in the last 3 months for private purposes. http://www.tuik.gov.tr/PreTablo.do?alt_ $\mathrm{id}=1028 \#$ Accessed May 16, 2019.

2. van den Eijnden RJJM, Lemmens JS, Valkenburg PM. The social media disorder scale. Comput Hum Behav 2016; 61:478487. [CrossRef]

3. Ryan T, Chester A, Reece J, Xenos S. The uses and abuses of Facebook: a review of Facebook addiction. J Behav Addict 2014; 3:133-148. [CrossRef]

4. Andreassen CS. Online social network site addiction: a comprehensive review. Curr Addict Rep 2015; 2:175-184. [CrossRef]

5. Fox J, Rooney MC. The Dark Triad and trait self-objectification as predictors of men's use and self-presentation behaviors on social networking sites. Pers Individ Diff 2015; 76:161-165.

6. Valkenburg PM, Peter J, Schouten AP. Friend networking sites and their relationship to adolescents' well-being and social selfesteem. Cyberpsychol Behav 2006; 9:584-590. [CrossRef]

7. Blackwell D, Leaman C, Tramposch R, Osborne C, Liss M. Extraversion, neuroticism, attachment style and fear of missing out as predictors of social media use and addiction. Pers Individ Diff 2017; 116:69-72. [CrossRef]

8. Monacis L, de Palo V, Griffiths MD, Sinatra M. Exploring individual differences in online addictions: the role of identity and attachment. Int J Ment Health Addict 2017; 15:853-868.

9. Bowlby J. A Secure Base: Parent-Child Attachment and Healthy Human Development. New York: Basic Books, 1988.

10. Ainsworth, MDS, Blehar MC, Waters E, Wall S. Patterns of Attachment: A Psychological Study of the Strange Situation. Oxford: Lawrence Erlbaum, 1978. [CrossRef]

11. Bartholomew K, Horowitz LM. Attachment styles among young adults: a test of a four-category model. J Pers Soc Psychol 1991; 61:226-244. [CrossRef]

12. Collins NL, Read SJ. Adult attachment, working models, and relationship quality in dating couples. J Pers Soc Psychol 1990; 58:644-663. [CrossRef]

13. Caplan SE. Relations among loneliness, social anxiety, and problematic Internet use. Cyberpsychol Behav 2006; 10:234242. [CrossRef]

14. Weidman AC, Fernandez KC, Levinson CA, Augustine AA, Larsen R J, Rodebaugh TL. Compensatory internet use among individuals higher in social anxiety and its implications for wellbeing. Pers Individ Diff 2012; 53:191-195. [CrossRef]

15. Hart J, Nailling E, Bizer GY, Collins CK. Attachment theory as a framework for explaining engagement with Facebook. Pers Individ Diff 2015; 77:33-40. [CrossRef]

16. Jenkins-Guarnieri MA, Wright SL, Johnson BD. The interrelationships among attachment style, personality traits, interpersonal competency, and Facebook use. Psychol Pop Media Cult 2013; 2:117-131. [CrossRef] 
17. Schimmenti A, Passanisi A, Gervasi AM, Manzella S, Fama FI. Insecure attachment attitudes in the onset of problematic Internet use among late adolescents. Child Psychiatry Hum Dev 2014; 45:588-595. [CrossRef]

18. Nitzburg GC, Farber BA. Putting up emotional (Facebook) walls? Attachment status and emerging adults' experiences of social networking sites. J Clin Psychol 2013; 69:1183-1190. [CrossRef]

19. Rosenberg M. Rosenberg self-esteem scale (RSE). "Acceptance and Commitment Therapy”, Measures Package 1965; 61(52).

20. Trzesniewski KH, Donnellan MB, Moffitt TE, Robins RW, Poulton R, Caspi A. Low self-esteem during adolescence predicts poor health, criminal behavior, and limited economic prospects during adulthood. Dev Psychol 2006; 42:381-390. [CrossRef]

21. Baumeister RF, Campbell JD, Krueger JI, Vohs KD. Does high self-esteem cause better performance, interpersonal success, happiness, or healthier lifestyles? Psychol Sci Public Interest 2003; 4:1-44. [CrossRef]

22. Proctor CL, Linley PA, Maltby J. Youth life satisfaction: a review of the literature. J Happiness Stud 2009; 10:583-630. [CrossRef]

23. McAdams TA, Rijsdijk FV, Narusyte J, Ganiban JM, Reiss D, Spotts E, et al. Associations between the parent-child relationship and adolescent self-worth: a genetically informed study of twin parents and their adolescent children. J Child Psychol Psychiatry 2017; 58:46-54. [CrossRef]

24. Armsden GC, Greenberg MT. The inventory of parent and peer attachment: individual differences and their relationship to psychological well-being in adolescence. J Youth Adolesc 1987; 16:427-454. [CrossRef]

25. Noom MJ, Dekovic M, Meeus WH. Autonomy, attachment and psychosocial adjustment during adolescence: a double-edged sword? J Adolesc 1999; 22:771-783. [CrossRef]

26. Arbona C, Power TG. Parental attachment, self-esteem, and antisocial behaviors among African American, European American, and Mexican American adolescents. J Couns Psychol 2003; 50:40-51. [CrossRef]

27. Birkeland MS, Melkevik O, Holsen I, Wold B. Trajectories of global self-esteem development during adolescence. J Adolesc 2012; 35:43-54. [CrossRef]

28. Leary MR, Baumeister RF. The nature and function of selfesteem: sociometer theory. Adv Exp Social Psychol 2000; 32:1-62.

29. Anthony DB, Wood JV, Holmes JG. Testing sociometer theory: self-esteem and the importance of acceptance for social decisionmaking. J Exp Soc Psychol 2007; 43:425-432. [CrossRef]

30. Leary MR, MacDonald G. Individual differences in self-esteem: a review and theoretical integration: In Leary MR, Tangney JP (editors). Handbook of Self and Identity. New York: The Guilford Press, 2003, 401-418.

31. Forest AL, Wood JV. When social networking is not working: individuals with low self-esteem recognize but do not reap the benefits of self-disclosure on Facebook. Psychol Sci 2012; 23:295302. [CrossRef]

32. Reis, HT, Shaver P. Intimacy as an Interpersonal Process: In Duck S, Hay DF, Hobfoll SE, Ickes W, Montgomery B M (editors).
Handbook of Personal Relationships. Chichester, England: John Wiley and Sons, 1988, 367-389. [CrossRef]

33. Marshall TC, Lefringhausen K, Ferenczi N. The Big Five, selfesteem, and narcissism as predictors of the topics people write about in Facebook status updates. Pers Individ Diff 2015; 85:35-40.

34. Błachnio A, Przepiorka A, Rudnicka P. Narcissism and selfesteem as predictors of dimensions of Facebook use. Pers Individ Diff 2016; 90:296-301. [CrossRef]

35. Andreassen CS, Pallesen S, Griffiths, MD. The relationship between addictive use of social media, narcissism, and selfesteem: findings from a large national survey. Addict Behav 2017; 64:287-293. [CrossRef]

36. Tutgun-Unal A, Deniz L. Development of the Social Media Addiction Scale. AJIT-e 2015; 6:51-70. (Turkish) [CrossRef]

37. Sumer N, Gungor D. Psychometric evaluation of adult attachment style scales in a Turkish sample and intercultural comparison. Turkish Journal of Psychology 1999; 14:71-106.

38. Cohen O, Finzi-Dottan R. Parent-child relationships during the divorce process; from attachment theory and intergenerational perspective. Contemp Fam Ther 2005; 27:81-99. [CrossRef]

39. Lench HC, Quas JA, Edelstein RS. My child is better than average: the extension and restriction of unrealistic optimism. J Appl Soc Psychol 2006; 36:2963-2979. [CrossRef]

40. Moller AC, Roth G, Niemiec CP, Kanat-Maymon Y, Deci EL. Mediators of the associations between parents' conditional regard and the quality of their adult-children's peer-relationships. Motiv Emot 2019; 43:35-51. [CrossRef]

41. Guloglu B, KarairmakO. Attachment styles and psychological tendencies in intimate relations in paternal loss in early childhood. Turkish Journal of Psychological Counseling and Guidance 2017; 7:99-115. (Turkish)

42. Imamoglu S, Imamoglu EO. Relationship between general and context-specific attachment orientations in a Turkish sample. J Soc Psychol 2006; 146:261-274. [CrossRef]

43. Zeyrek EY, Gencoz F, Bergman Y, Lester D. Suicidality, problemsolving skills, attachment style, and hopelessness in Turkish students. Death Stud 2009; 33:815-827. [CrossRef]

44. Cuhadaroglu F. (1986). Self-esteem in adolescents. Specialization Thesis, Hacettepe University Medical Faculty Psychiatry Department, Ankara, 1986. (Turkish)

45. Arbuckle JL. Amos (Version 22.0), Computer Program, SPSS/ IBM, Chicago, 2013.

46. McDonald RP, Ho M-HR. Principles and practice in reporting structural equation analyses. Psychol Methods 2002; 7:64-82.

47. Hooper D, Coughlan J, Mullen M R. Structural equation modelling: guidelines for determining model fit. EJBRM 2008; 6:53-60.

48. Edlund, J.E, Sagarin BJ. Sex differences in jealousy: a 25-year retrospective. Adv Exp Soc Psychol 2017; 55:259-302. [CrossRef]

49. George C, Kaplan N, Main M. Adult attachment interview. Unpublished manuscript 1996. http://library.allanschore.com/ docs/AAIProtocol.pdf. Accessed May 27, 2019. 
50. Chen A. From attachment to addiction: the mediating role of need satisfaction on social networking sites. Comput Human Behav 2019; 98:80-92. [CrossRef]

51. Monacis L, De Palo V, Griffiths MD, Sinatra M. Social networking addiction, attachment style, and validation of the Italian version of the Bergen Social Media Addiction Scale. J Behav Addict 2017; 6:178-186. [CrossRef]

52. Demircioglu ZI, Goncu Kose A. Effects of attachment styles, dark triad, rejection sensitivity, and relationship satisfaction on social media addiction: a mediated model. Curr Psychol 2018. [CrossRef]

53. Savc1 M, Aysan F. The role of attachment styles, peer relations, and affections in predicting Internet addiction. Addicta: The Turkish Journal on Addictions 2016; 3:401-432. [CrossRef]

54. Eichenberg C, Schott M, Decker O, Sindelar B. Attachment style and internet addiction: an online survey. J Med Internet Res 2017; 19:e170. [CrossRef]

55. Cacioppo M, Barni D, Correale C, Mangialavori S, Danioni F, Gori A. Do attachment styles and family functioning predict adolescents' problematic internet use? A relative weight analysis. J Child Fam Stud 2019; 28:1263-1271. [CrossRef]

56. Man KO, Hamid PN. The relationship between attachment prototypes, self-esteem, loneliness and causal attributions in Chinese trainee teachers. Pers Individ Diff 1998; 24:357-371.

57. Andreassen CS, Billieux J, Griffiths MD, Kuss DJ, Demetrovics Z, Mazzoni E, et al. The relationship between addictive use of social media and video games and symptoms of psychiatric disorders: A large-scale cross-sectional study. Psychol Addict Behav 2016; 30:252-262. [CrossRef]

58. Skinner BF. Contingencies of Reinforcement. East Norwalk: Appleton-Century-Crofts, 1969.

59. Rosenberg M. Society and the Adolescent Self-Image. Princeton, NJ: Princeton University Press, 1965. [CrossRef]

60. Chou WYS, Hunt YM, Beckjord EB, Moser RP, Hesse BW. Social media use in the United States: implications for health communication. J Med Internet Res 2009; 11:e48. [CrossRef] 